\title{
Curvularia lunata as, a dominant seed-borne pathogen in Dalbergia sissoo Roxb: Its location in seed and its phytopathological effects
}

\author{
Sarika Gupta ${ }^{1 \star}$, Ashish Dubey ${ }^{2}$ and Tribhuwan Singh ${ }^{3}$ \\ ${ }^{1}$ Department of Bioscience and Biotechnology, Banathali University, Rajasthan, India. \\ ${ }^{2}$ Department of Botany, Agarwal P. G. College, Jaipur, India. \\ ${ }^{3}$ Department of Botany, University of Rajasthan, Jaipur, India.
}

Received 7 February, 2017; Accepted 8 March, 2017

\begin{abstract}
Dalbergia sissoo (shisham) seeds naturally infected with Curvularia lunata showed either black discoloration (1.25 to $8.75 \%)$ or appeared dull (0.50 to $10.0 \%)$. When they were incubated, they yielded pure growth of the pathogen. During location studies, cleared whole mount preparation and component plating revealed the presence of infection restricted to the seed coat and cotyledons of asymptomatic seeds. However, this pathogen penetrates the deeper tissue of symptomatic seeds to the embryonic axis. Due to heavy infection, the disintegration of cells results in the formation of lysogenic cavities. The fungus enters the seeds through the hilar region and epidermal cells of the seed coat to the aleurone layer and finally into the cotyledonary cells of the embryo. The pathogen is both externally and internally seed-borne. The internal inoculum affected seed germination, viability and caused high total (pre-and post-emergence) losses (15 to $80 \%$ ). The pathogen was transmitted from seed to seedling causing heavy losses to the tree plantation.
\end{abstract}

Key words: Dalbergia sissoo, Curvularia lunata, pre-and post-emergence losses, phytopathological effect.

\section{INTRODUCTION}

Shisham (Dalbergia sissoo Roxb.), an important legume tree belonging to the family of Fabaceae and subfamily Papilionaceae, is widely grown throughout the world and in India (Ashour and El-Kadi, 1958; Champion and Seth 1968). It grows as an ornamental roadside tree (Anonymous, 1952; NAS, 1983) and is used for medicinal purposes (Nadkarni, 1954). Leaf spot disease caused by Curvularia lunata results in severe losses to Shisham plantations (Bhowmick and Vardhan, 1981). Curvularia is defined as a type of species $C$. lunata (Wakker) Boedijn, which appears as shiny velvety-black, and has fluffy growth on the colony surface. It is distinguished by septate, dematiaceous hyphae producing brown, geniculate conidiophores. Its conidia are curved slightly to distinctly transversely septate with an expanded third cell from the pore end of the conidium (Nelson and

*Corresponding author. E-mail: sarika.ashish@gmail.com. Tel: +919414461423.

Author(s) agree that this article remains permanently open access under the terms of the Creative Commons Attribution License 4.0 International License 
Table 1. Seed samples of Dalbergia sissoo infected by Curvularia lunata in Jaipur.

\begin{tabular}{|c|c|c|c|c|c|c|}
\hline \multirow{2}{*}{ Location } & \multirow{2}{*}{ No. of samples } & \multicolumn{2}{|c|}{ Dry seed examination } & \multicolumn{2}{|c|}{ In standard blotter method } & \multirow{2}{*}{ In PDA test } \\
\hline & & Black & Dull & Untreated & Pretreated $^{\star}$ & \\
\hline Bani Park & 3 & 3 & 3 & 2 & 2 & - \\
\hline Forest Training Centre & 3 & 1 & 2 & 3 & 3 & 2 \\
\hline Jhalana Natural Garden & 3 & 3 & 2 & 3 & 3 & 2 \\
\hline Police Academy & 12 & 12 & 9 & 9 & 6 & - \\
\hline Sanganer & 3 & 1 & 3 & 3 & 2 & - \\
\hline Seed Market & 9 & 9 & 9 & 8 & 6 & 2 \\
\hline University Campus & 12 & 12 & 12 & 10 & 9 & 2 \\
\hline VidhanSabhaBhawan & 3 & 2 & 1 & - & - & - \\
\hline World Forestry Arboretum & 3 & 3 & 3 & 3 & 2 & 2 \\
\hline Total & 51 & 46 & 44 & 41 & 33 & 10 \\
\hline
\end{tabular}

${ }^{*}$ Pretreated with $3 \%$ chlorine for five minutes.

Haasis, 1964). C. lunata is internally and externally seedborne causing pre- and post-emergence mortality. Its pathogenicity was confirmed by artificial inoculation of healthy host tissue which resulted in disease.

Acacia nilotica has been reported during a disease survey in 2 nurseries in Jabalpur, Madhya Pradesh, India as a new host for $C$. lunata (Singh and Jammaluddin, 1995). For analysis of the host-parasite relationship (shisham and Curvularia sp.), artificial inoculation of the eight days old Curvularia sp. suspension, was sprayed on leaves of the healthy plant to prove its pathogenicity. This study revealed the occurrence of a new foliar disease with irregular leaf spots that progressed from the leaf margin to the centre of the lamina. The fungus is identified as Curvularia sp. while the pathogenicity test proved Koch's postulate (Sharma et al., 2012).

Four criteria were established by Robert Koch to identify the causative agent of a particular disease: the pathogen must be present in all cases of the disease, should be isolated from the diseased host and be grown in pure culture and designated as Koch's postulate or pathogenicity test to determine the host-parasite relationship (Marshall et al.,1985; Kamaluddeen and Lal, 2013). There is no information on the seed-borne nature of $C$. lunata in $D$. sissoo seeds. Therefore, the present study was carried out to know the location of the pathogen, its role in disease transmission and its phytopathological effects.

\section{MATERIALS AND METHODS}

Fifty-one seed samples collected from nine locations around Jaipur, India (Table 1) were subjected to dry seed examination and incubation tests by Standard Blotter Method (SBM) and Potato Dextrose Agar (PDA) plate test (ISTA, 1990). For the dry seed examination, shape (normal, flat, brown, reniform, asymptomatic), various discolourations (dark brown, white, black, green) and deformities (shiny, dull) were recorded. Seeds were incubated on moistened blotters with and without pretreatment with 3\% chlorine for five minutes.
For PDA test, pretreated seeds were sown (10 seeds per plate) in Petri plates of $60 \times 15 \mathrm{~mm}$ size containing PDA medium. Two seed samples were selected with high percent of incidence of the pathogen, one from the forest training centre and one from a seed market (sample accession numbers 3 and 18, respectively) with a high incidence of Curvularia lunata. These samples were used for location and transmission studies. The seeds are categorised as asymptomatic and symptomatic (weakly and heavily infected) based on the severity of the infection.

Location of the pathogen in different seed components was studied using component plating (10 seeds per category per sample), hand cut and microtome sectioning (five seeds per category per sample) (Singh, 2002). Transmission of seed-borne inoculum from seed to seedling/plant was studied using Petri plate method and growth tests (ISTA, 1990). For Petri plate method, four replicates of 100 pretreated seeds were sown on moistened blotters (10 seeds per plate), grown in water agar test tube seedling symptom test (1 seed/test tube), respectively. Germination, the incidence of the pathogen, seedling-symptoms, and seedling mortality were observed.

\section{RESULTS}

Out of the 51 seed samples collected during the study, they comprised either black seeds $46(1.25$ to $8.75 \%)$ or dull-appearing seeds $44(0.50$ to $10.0 \%)$ carrying infection of $C$. lunata (Table 1). Upon incubation, seeds yield pure growth of the pathogen (Figure 1A). The incidence of $C$. lunata from untreated and pretreated seeds in the SBM test was $41(2.0$ to $54.0 \%)$ and $33(2.0$ to $18.0 \%)$, respectively and $10(10.0$ to $30.0 \%)$ in the PDA test. Incidence was high in the samples from the Forest Training Center, Seed Market and University Campus (Table 1).

The sample accession was 3 and 18 , subjected to histochemical localisation studies. During component plating, pathogen was detected as 15 and $25 \%$ on the seed coat, 10 and $15 \%$ on cotyledons and $0.5 \%$ on the embryonal axis of asymptomatic seeds of both samples. Characteristic mycelium with sympodial succession in conidia of $C$. lunata was observed in 50 to $80 \%$ on seed 


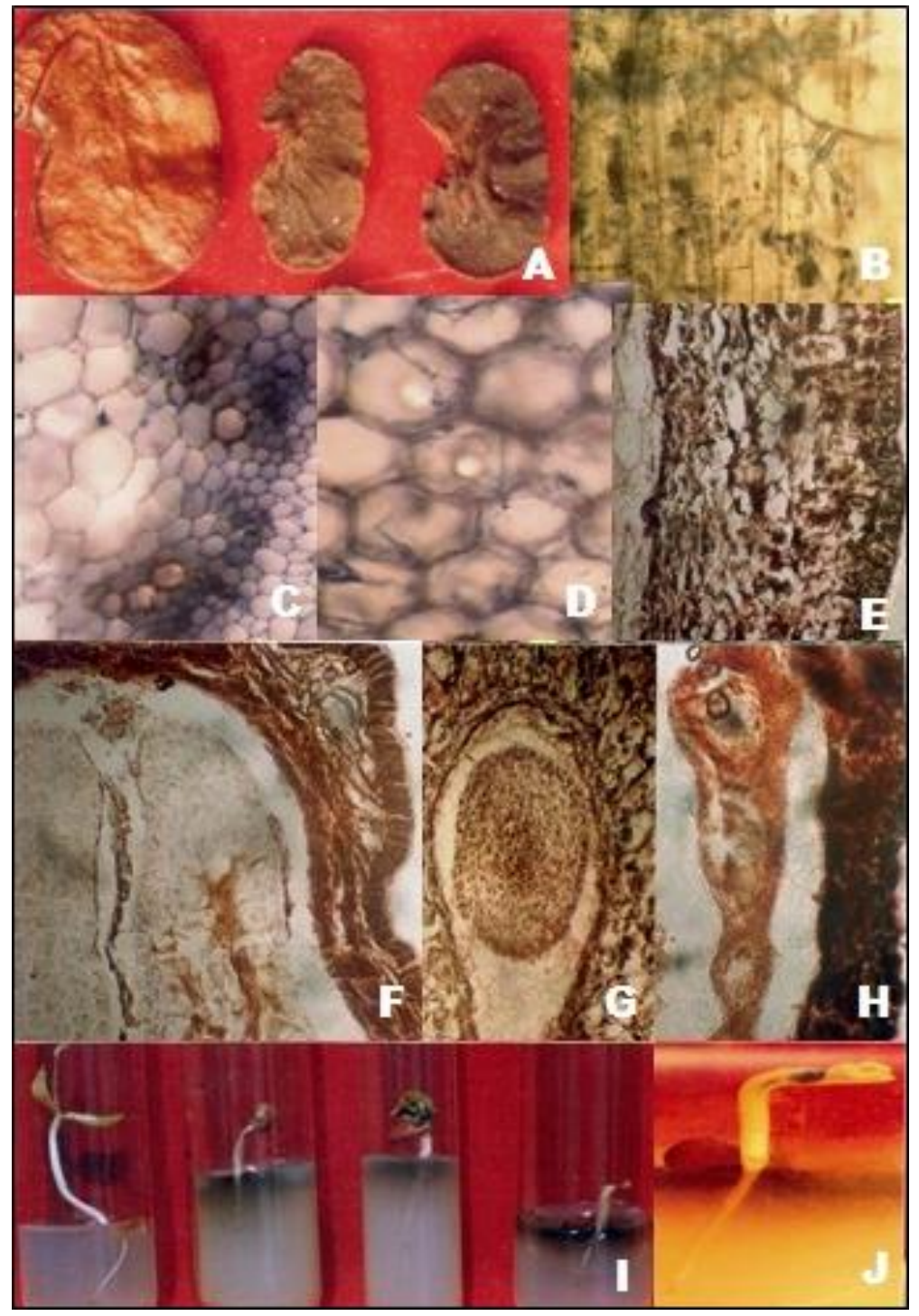

Figure 1. Histopathological and cytopathological localisation of Curvularia lunatain Dalgerbia sissoo seeds. (A)Seeds showing discolorations caused by $C$. lunata with scattered brown patches and compressed hilar region. $\times 18$. (B) Cleared wholemount preparation of cotyledon with mycelia network. $\times 350$. (C, D) Hand cut sections of seeds infected with $C$. lunata. Inter- and intra-cellular mycelium in cells of the cotyledons $(C ; \times 350)$ and embryonic axis $(D ; \times 700)$. $(E-H)$ Microtome sections of seeds infected with $C$. lunata. (E)T.S. part of seed showing mycelial bits and cellular disaggregation in the seed coat $(\times 700)$. (F)T.S. part of weakly infected seeds showing mycelial aggregation in and around the cells of the seed coat, cotyledons and the space between cotyledons $(\times 700)$. (G) Inter- and intracellular mycelium in cells of seed coat and embryonal axis $(\times 350)$. (H) Disintegrated cells of cotyledons of heavily infected seed $(\times 700)$. (I, J) Phytopathological studies in water agar seedling symptom test showing various degrees of infection.

(I) Normal and infected seedlings. (J) Characteristic symptoms of $C$. Iunata in the root, collar and the primary leaves of a weakly-infected seedling.

coat, 40 to $75 \%$ on cotyledons and 25 to $65 \%$ on the embryonal axis of weakly and heavily symptomatic seeds of samples 3 and 18, respectively (Figure 2). Another study in histochemical localisation was cleared whole- mount preparations, infection detected as $40,20 \%$ in the seed coat and $20,20 \%$ in cotyledons of asymptomatic seeds of the two samples, respectively.

Broad, dark brown, septate, branched inter- and intra- 


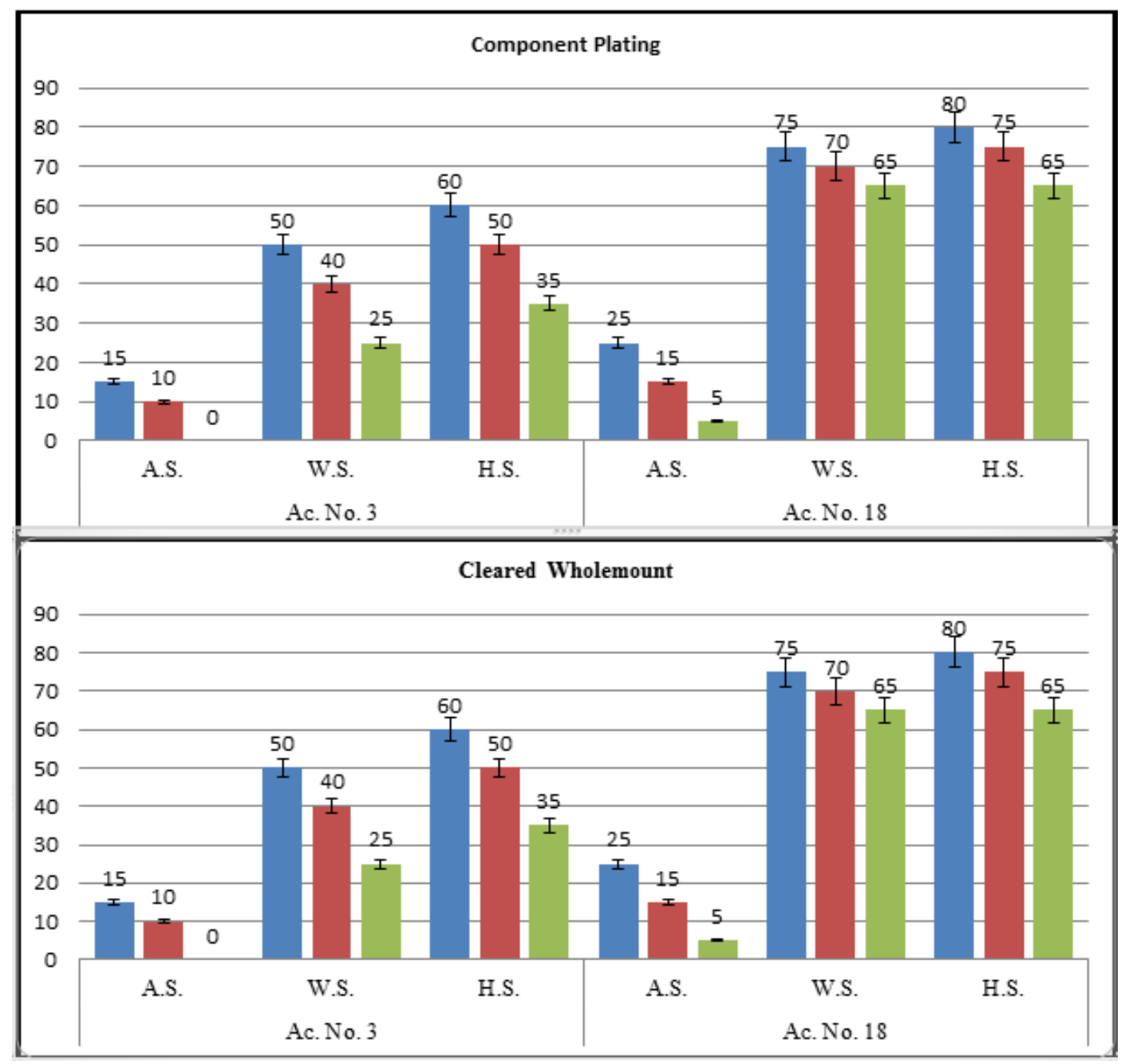

Figure 2. Percent incidence of Curvularia lunata in various components of seed and its cleared whole mount preparation (using seed sample with accession number 3 and 18 respectively) showing error bars with percentage. Note: Blue- Seed Coat, Red- Cotyledons and- Green Embryonal axis. Ac. No.= Accession Number of the seed samples collected during study; A S.= Asymptomatic; Symptomatic(W S. = Weakly Symptomatic and H S. = Heavily Symptomatic).

cellular mycelium was detected in symptomatic seeds (with weak and heavy infection). It varied from 60 to $100 \%$ in seed coat, 60 to $80 \%$ in cotyledons and 50 to $80 \%$ in embryonal axis in two samples, respectively (Figures 2 and $1 \mathrm{~B}$ ).

In localisation studies of pathogen in seed, hand-cut (Figure $1 \mathrm{C}$ to $\mathrm{D}$ ) and microtome sections (Figure 1E to $\mathrm{H}$ ) revealed infection with pathogen. Five seeds each of the two samples revealed that, asymptomatic seed's mycelium was not observed in the deeper tissues of the seed. Mycelial fragments and hyphal parts were observed in epidermal and subepidermal cells of the seed coat. Whereas weakly symptomatic seed's mycelium, ramified the layers of the seed coat and invaded into cotyledons and rarely hyphal bits seen in embryonic axis (Figure $1 \mathrm{~A}$ to $\mathrm{H}$ ). Seed coat cells became irregularly elongated and disfigured, showing the disintegration of the cell wall.

In heavily symptomatic seeds, characteristic inter- and intracellular mycelium was detected in all seed components. Both the cotyledons were compressed, showing necrotic regions and lytic cavities. The cells of the seed coat and cotyledons become enlarged, disfigured, deformed and depleted. Seed coat and cotyledon cells were dead, containing brown pigmented cytoplasm filled with hyphal fragments (Figure 1F).

Due to heavy infection, the disintegration of cells resulted in the formation of lysogenic cavities. Dense hyphal networks were observed in and on the cells of the embryonic axis (Figure 1G). The spread of hyphae was detected from the hilar region to epidermal cells of seed coat followed by aleurone layer and cotyledonary cells of 


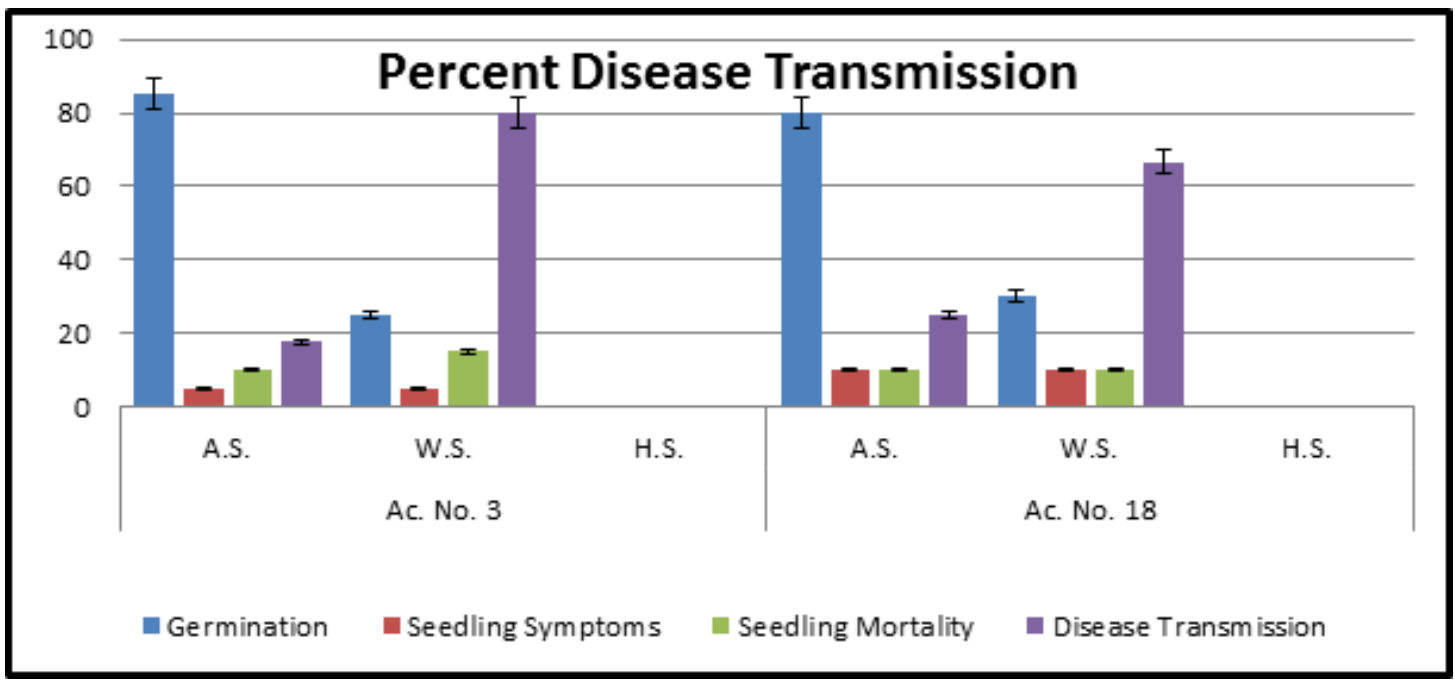

Figure 3. Phytopathological effects of Dalbergia sissoo seeds naturally infected with Curvularia lunata in Water-agar seedling symptom test (WASST) and pot experiment showing error bars with percentage.

the embryo (Figure 1F).

During transmission studies in standard blotter method, germination was started after one day of incubation as $85,80 \%$ in the two samples studied and on the 12th day, it declined to $25,30 \%$ of sowing in asymptomatic seeds and weakly symptomatic seeds. The seedling exhibited high pre- and post-emergence mortality; whereas, heavily symptomatic seeds failed to germinate leading to $100 \%$ pre-emergence mortality due to fungal growth and seed rotting. For water agar seedling symptom test, germination was $95,90 \%$ in asymptomatic seeds and 15 , $25 \%$ in weakly symptomatic seeds on the 14 th day of sowing of both samples (Figure 3 ).

Total pre- and post-emergence loss and disease transmission varied from $15,15,17.6,25.0 \%$ and 45,35 , $80.0,66.6 \%$ in asymptomatic and weakly symptomatic seeds of the two samples, respectively (Figure 3 ). Initial signs of disease symptoms appeared on the 4th day of sowing; the root-shoot transition region became brown from where it spreads towards the root tip. The roots were poorly developed and stunted. Subsequently on 8 to10th day, brown streak developed on transition region, brown necrotic spots appeared on the cotyledon leaves and finally rotting occurred in the whole seedling (Figure $1 \mathrm{I}$ and $\mathrm{J}$ ).

\section{DISCUSSION}

Study on histopathological and phytopathological effects of seed-borne nature of $C$. lunata on Dalbergia sissoo Roxb was found to be limiting but the present study gave a comprehensive account by the review. The pathogen was found to be externally- and internally seed- borne, having characteristic feature that can be recognised during dry seed examination and was confirmed by histopathological and phytopathological studies. Similar observations in seed and seedling rotting were reported in sorghum due to C. lunata (Rastogi et al., 1990; Kamaluddeen and Lal, 2013). Cui and Sun (2012) reported the incidence of $C$. lunata in Nelumbo nucifera while Singh (2002) reported similar symptoms with high pre- and post-emergence losses and failure in germination, due to heavy infection. The pathogenicity was confirmed by artificial inoculation of healthy plant parts which resulted in the appearance of disease. Such studies were supported by a research of Ashour and ElKadi (1958).

Another study reported Acacia nilotica as a new host for $C$. lunata which studied the cultural and morphological characters of the pathogen (Singh and Jamaluddin, 1995). Pathogenicity of the fungus was proved by spraying eight days old suspension of $C$. lunata on leaves. In a study of some dominant seed borne fungi of a rice variety, twenty dominant fungi were found to be associated by blotter method; agar plate method showed that species of Aspergillus, Fusarium, Alternaria and Curvularia are the dominant genera affecting seed germination and seedling vigour (Islam and Borthakur, 2012). The study suggested that shisham is an important multipurpose tree with great economic importance. But this tree has been devastated by die back disease due to four fungi (Fusarium solani, Botryodiplodia theobromae, C. Iunata and Ganoderma lucidum). Ahmad et al. (2013) evaluate the potential role of these fungi in shisham die back disease. The seeds of Dalbergia sissoo were collected from 10 locations in Bihar. Seeds were placed on PDA medium and observed for the growth of fungus after 5 to 10 days of incubation.

This result indicates six genus of fungi viz. Alternaria 
alternata, Penicillium citrinum, Helmenthosporium sp., $C$. lunata, Geotricum sp, respectively (Naz et al., 2015). The present study revealed that the infected seeds are asymptomatic or symptomatic (weakly and heavily infected). C. lunata was mostly found to be associated with seeds with black discolorations along with dull appearance, and was both externally and internally seedborne. The role of seed-borne inoculums of $C$. lunata in disease transmission has been investigated in shisham (Bhowmick and Vardhan, 1981), in Sudan grass (Komoto and Hori, 1983) and Pearl millet (El-Zayat et al., 1990). However, its pathogenicity was confirmed by artificial inoculation in healthy host tissue, which resulted in disease.

During transmission studies, the pathogen moved from seed to seedling/plant which caused a high pre- and post-emergence loses, and symptoms appear as, brown streak transition region and brown necrotic spots primary leaves. Later the whole seedling got rotten and was succumbed to death. According to a study, Curvularia sp. is a highly pathogenic fungus with main seedling rot, causing agent in Sudan grass (El-Zayat et al., 1990; Rajput et al., 2010). Similar results had been reported by another study on $D$. sissoo, indicating a reduction in seed germination percentage $(50.00 \%)$ in soil infested with $F$. solani. Seedling mortality was $93.33 \%$ followed by soil infested with $R$. solani $(60.00 \%)$ with a mortality rate of $66.66 \%$ and $C$. lunata of $70.00 \%$. The seedling mortality rate of $42.85 \%$ is compared to that of $F$. moniliformi and F. oxysporum, respectively (Nadkarni, 1954).

\section{Conclusion}

The pathogen $C$. lunata is both externally and internally seed-borne. The internal inoculum affected seed germination, and viability which caused high total (preand post-emergence) losses. This pathogen was transmitted from seed to seedling, causing heavy losses to tree plantation.

\section{CONFLICT OF INTERESTS}

The authors have not declared any conflict of interests.

\section{REFERENCES}

Ahmad BI, Khan RA, Siddiqui MT (2013). Incidence of dieback disease following fungal inoculations of sexually and asexually propagated shisham (Dalbergia sissoo). For. Pathol. 43:77-82.

Anonymous (1952). The Wealth of India. Raw Materials, Vol. HI,D-E, CSM New Delhi. http://www.niscair.res.in/

Ashour WE, El-Kadi MM (1958). Cultural studies of Fusarium semitectum Alternaria tenuis and Rhizoctonia solani which cause damping - off of tomato seedlings. A'in Shams Sci. Bull. 3:57-68.

Bhowmick BN, Vardhan V (1981). Antifungal activity of some leaf extracts of medicinal plants on Curvularialunata. Phytopathologicalnote. Indian Phytopathol. 34:385-386.

Champion HG, Seth SK (1968). A Revised Survey of the Forest Types of India, Manager of Publication, Delhi.

Cui RQ, Sun XT (2012). First Report of Curvularia lunata Causing Leaf Spot on Lotus in China. Plant Dis. 96(7):1068-1069.

El-Zayat MM, Mansour IM, Moursy MA, Abdel-Fattach MND (1990). Stalk and root rots of certain cereal forage crops in Egypt. Ann. Agric. Sci. Moshtohor 28(3):1525-1537.

Islam NF, Borthakur SK (2012). Screening of mycota associated with Aijung rice seed and their effects on seed germination and seedling vigour. Plant Pathol. Quar. 2:75-85.

ISTA (1990). International rules of seed testing. Seed Sci. Technol. 18:299-513.

Kamaluddeen SS, Lal AA (2013). A New Blight Disease Of Rice Caused By Curvularia Lunata From Uttar Pradesh. Int. J. Agric. Sci. Res. 3(5):13-16.

Komoto Y, Hori M (1983). Factors affecting development of Curvularia leaf spot of sudan grass. Bull. Chugoker Natl. Agric. Exp. Stn. 20:1523.

Marshall BJ, Armstrong JA, McGechie DB, Glancy RJ (1985). Attempt to fulfil Koch's postulates for pyloric Campylobacter. Med. J. Aust. 142(8):436-439.

Nadkarni KM (1954). Indian Material Medico, $3^{\text {rd }}$ edition, Popular Book Depot, Bombay and Dhootapapeshwar Prakashan Ltd.

NAS (1983). Firewood Crops: Shrub and Tree Species for Energy Production, Vol. 11, National Academy of Science Press, Washington, D.C.

Naz H, Naz A, Pandey A (2015).Studies on Fungi Associated with Dalbergiasissoo Roxb.ex. DC, Lambert Academic Publishing.

Nelson RR, Haasis FA (1964). The Perfect Stage of Curvularia lunata. Mycologia 56(2):316-317.

Rajput NA, Pathan MA, Rajput Q, Jiskani MM, Lodhi M, Rajput SA, Khaskhal MI (2010). Isolation of fungi associated with shisham trees and their effect on seed germination and seedling mortality. Pak. J. Bot. 42:369-374.

Rastogi R, Singh T, Singh D (1990). Infection of Curvularialunatain all sorghum seeds. J. Indian Bot. Soc. 69:71-73.

Sharma P, Singh N, Verma OP (2012). First report of Curvularia leaf spot, caused by Curvulariaaffinis on Dalbergiasissoo. For. Pathol. 42:265-266.

Singh B, Jammaluddin (1995). Acacia nilotica:new host of Curvularia. Indian Forester 121(2):161.

Singh R (2002). Seed and Seedling Diseases of Pearl Millet and their Control, Ph.D. Thesis, University of Rajasthan, Jaipur. 